\title{
Causal authorship and the equality principle: a defence of the acts/omissions distinction in euthanasia
}

Marc Stauch Nottingham Trent University, Nottingham

\begin{abstract}
This paper defends the acts/omissions distinction which underpins the present law on euthanasia, from variou criticisms (including from within the judiciary itself), and aims to show that it is supported by fundamental principles. After rejecting arguments that deny the coherence and/or legal relevance of the distinction, the discussion proceeds to focus on the causal relationship between the doctor and the patient's death in each case. Although previous analyses, challenging the causal efficacy of omissions generally, are shown to be deficient, $i$ is argued that in certain cases of causing death by omission the causal authorship of the doctor lapses. The final part of the paper examines why this should be morally significant and proposes an answer in terms of the principle of equality. Assuming all other factors are equal, the infringement of this principle provides an additional reason against actively killing a patient, which is not present in cases of passively letting die.

(Fournal of Medical Ethics 2000;26:237-241)
\end{abstract}

Keywords: Euthanasia; acts and omissions; causation; respect for life

\section{Introduction}

The current attitude of the law towards the practice of euthanasia is as well known as it is controversial. In two cases, from 1992 and 1993 respectively, the courts took a stand based on the well-established criminal law distinction between acts that bring about death and omissions to prevent death, or, as it is often termed, between "active" and "passive" euthanasia. Thus, in R v Cox (1992), ${ }^{1}$ a doctor who gave his patient a lethal injection of potassium chloride, after she begged him to release her from her suffering, was convicted of attempted murder. By contrast, in Airedale NHS v Bland (1993), ${ }^{2}$ the House of Lords upheld a declaration granted by the High Court, that a patient in a PVS (persistent vegetative state) for over three and a half years could have his life-sustaining regime of hydration, nutrition and antibiotics discontinued, so allowing his death.

Though subsequently affirmed by a House of Lords select committee, ${ }^{3}$ the position taken by the courts has been the focus of sustained criticism from two opposing sides. On the one hand are those conservative critics who argue that, in permitting the intentional causing of Tony Bland's death, the courts have abandoned their traditional commitment to the sanctity of life, and are already complicit in what is effectively judicial murder. ${ }^{4}$ On the other hand, there are more radical voices, which urge a reappraisal of this whole debate and the promotion of quality of life as the benchmark for medical decision making at the end of life. To these critics, the precise mechanics of how death occurs are of secondary importance to the pain or pleasure of the life-holder's states of consciousness. ${ }^{5}$ Furthermore, in campaigning for the legalisation of voluntary active euthanasia at least, they have bolstered their argument by an appeal to the autonomy rights of competent patients who desire to die, but require assistance to do so.

What critics from both sides have in common is that they deny that the acts/omissions distinction upheld by the courts has any intrinsic merit. Moreover, they derive encouragement in this from some of the less than wholehearted endorsements of the distinction forthcoming from the judiciary itself. In Bland, Lord Mustill suggested that reliance upon it had rendered the law "morally and intellectually misshapen". ${ }^{6}$ Similarly Lord BrowneWilkinson, having asked, "[h] ow can it be lawful to allow a patient to die slowly, though painlessly, over a period of weeks from lack of food but unlawful to produce his immediate death by a lethal injection, thereby saving his family from yet another ordeal to add to the tragedy that has already struck them" admitted that he found it "difficult to find a moral answer to that question". ${ }^{7}$

In this paper, it will be argued that such judicial doubts about the distinction are in fact misplaced, and that, at a deep level, it does enjoy a moral foundation. Even leaving aside other, policy-based arguments, it is submitted that this in itself provides plausible grounds for the distinction to continue to underpin the law in this area.

Is the acts/omissions distinction coherent? Some critics of the current state of the law have doubted, as a matter of preliminary argument, that the acts/omissions distinction, which the courts have sought to apply, is a coherent one even by its own lights. Thus it is sometimes said that the law adopts arbitrary labels for what in a given instance counts as an omission rather than an act, so as to post-rationalise the desired judicial conclusion. For example, in the context of withdrawing or withholding medical treatment, the doctor's conduct will often, it is claimed, really involve an act such as 
disconnecting a feeding tube or turning off a ventilator. In fact, as commentators such as Glanville Williams have argued, the refusal to characterise what the doctor does on such occasions as an act has a perfectly defensible and principled basis. It derives from the use of a wider and, it is suggested, more plausible, criterion of action than one of voluntary physical movement alone, and directs attention to whether what the agent does represents an interference in the normal course of nature. ${ }^{8}$ This analysis met with the approval of Lord Goff in Bland, who commented:

"It is true that it may be difficult to describe what the doctor actually does as an omission, for example where he takes some positive step to bring the life support to an end. But discontinuation of life support is, for present purposes, no different from not initiating life support in the first place. In each case, the doctor is simply allowing his patient to die in the sense that he is desisting from taking a step which might, in certain circumstances, prevent his patient from dying as a result of his pre-existing condition." ${ }^{9}$

It has been suggested that, if one is prepared to regard the doctor's conduct here as an omission, then one must logically hold that some maliciously motivated interloper-for example the patient's avaricious nephew who will gain a fortune upon the patient's death - who sneaks in and switches off the machine is equally guilty only of an omission. ${ }^{10}$ Lord Goff, however, rejected this possibility in the Bland case and, it is submitted, was correct to do so. The doctor artificially sustaining life has brought what may be regarded as a second "nature" into being in order to counteract the threat presented by brute nature to the patient's survival. The malicious interloper's conduct equates to an interference with this second "nature" and qualifies, on the analysis previously offered, as an act. By contrast, where the doctor switches the machine off, this represents a cessation of his or her own previous interference in brute nature, and is properly regarded as an omission.

Of course, in so far as the doctor ceases treatment for improper reasons (suppose that it is he who is desirous of gaining the patient's fortune), then the fact that he has omitted rather than acted in such circumstances will make no difference to his liability. That is because, unlike the general position as between strangers (where liability does not attach at common law for a simple failure to rescue), the doctor-patient relationship imports a duty on the doctor's part to act in his patient's best interests. This duty includes, prima facie, an obligation to treat the latter in order to prevent death where possible.

The fact that an omission to treat will, in such circumstances, attract the censure of the law (just as much as an act would) has led other commentators to find a second basis for doubting the utility of the acts/omissions distinction. According to them, even assuming the distinction to be conceptually coherent, it is one lacking in legal relevance. Instead, we should do better to conceive of the conduct required of doctors treating patients at the end of life in terms of duties, and recognise that these may, under the existing law, demand acting as much as forbearance from acting on the doctor's part. ${ }^{11}$ However, whilst it is certainly true that the question of whether an omission will be culpable depends on whether there was a duty to act, this does not establish that the acts/omissions distinction is unimportant. Rather, all the argument shows is that the fact death occurs by way of an omission is not always sufficient for the omitting agent to escape liability: there must also be the absence of a duty to act. On the other hand, that death should so occur does appear to be necessary - the doctor who omits to treat and thus allows his patient to die is at least in the frame for legal exoneration. By contrast, his colleague who actively kills is automatically liable. ${ }^{12}$

\section{Moral weight}

It is submitted then, that the acts/omissions distinction is coherent, and remains central in informing the different attitude of the law towards active as opposed to passive instances of euthanasia. The next question is whether, and if so what, underlying moral weight can be attached to the distinction. Of course, there may be sound policy reasons for the law to hold to such a distinction: I am thinking of such things as fears of slippery slopes towards active non-voluntary euthanasia, provoking anxiety among the vulnerable and elderly, undermining the perception of doctor as healer, etc. However, such arguments have a speculative character, which makes them vulnerable to arguments that draw attention to the good consequences that might also follow a policy of legalising voluntary active euthanasia (such as sparing the suffering-and respecting the wishes - of certain patients). If it were simply a case of trying to balance out the good versus bad consequences of legalising it, there would at least be an argument for an experiment in permitting voluntary active euthanasia to occur in carefully controlled circumstances.

A second matter, which will be ignored in the following discussion, is the contingent difference that, in practice, may be found in agents' motivations in cases of killing as opposed to letting die. As commentators such as James Rachels have pointed out, ${ }^{13}$ the fact (if it is one) that agents who kill typically have more reprehensible motives than those who let die, is irrelevant to the euthanasia debate. It may be assumed, in relation to voluntary euthanasia of both the active and passive forms, that the same (humane) motives are involved.

Instead, in what follows, it will be argued that a key formal difference between active and passive euthanasia resides in the causal relationship between the doctor and the death of the patient. Secondly, and equally important, it will be suggested that this intrinsic difference is morally significant. These two contentions are the subject of the two remaining sections of this paper. 
A difference in causality

At first glance, an omission, for example a doctor's failure to tend to his patient, is just as liable to be regarded as the cause of some subsequent event, say the patient's death, as a positive act, such as giving a lethal injection, would be. Certainly, applying the traditional "but for" test, we can, and often do, find that omissions feature as necessary conditions for given outcomes: "but for the doctor's failure to provide treatment, the patient would have lived". Nevertheless, some commentators have denied that omissions, properly understood, can have causative impact, and this on two distinct grounds. First, they argue that an omission represents "nothing", ie one can point to no voluntary physical movement in the world on any agent's part. Secondly, it is said that if once one cites the failure to act of one agent as having caused a given outcome, one is logically committed to holding the similar failure of every other agent to be just as much a cause of the outcome in question. ${ }^{14}$ As they stand, these arguments can, I think, clearly be shown to be fallacious. ${ }^{15}$ Even so, it will be suggested that, ultimately, they serve to cast light on a genuine difference between the causation of harm by action as opposed to omission.

To assess the arguments properly, it is helpful to employ a fuller model of causation than the partial picture offered by the "but for" test. Such a model is in fact available in the form of the NESS (necessary element in a sufficient set) test, which, in recent years, has increasingly won the acceptance of tort lawyers. ${ }^{16}$ The latter test asks if the factor we have provisionally identified as "the cause" of some given outcome formed part of a causal set sufficient for such an outcome to follow. It thus renders explicit the truth, first recognised by J S Mill, that events in the world come about through the workings of complexes of necessary conditions. For example, in the case of a man who takes poison, that fact alone is not sufficient for his death: it is only so in conjunction with a host of other conditions, of both a positive and negative nature, including the state of the man's metabolism and his subsequent failure to take an antidote (assuming there is one).

\section{Normal features}

Admittedly, not all of such necessary conditions have an equal claim upon our attention. Many of them are simply normal features of the background situation, which are present alike on occasions when outcomes calling for a causal explanation occur and when they do not. In the last example this is true of the underlying metabolism of the poisoned man. Assuming that this did not differ significantly from the metabolisms of other men, mentioning it serves no explanatory purpose in determining why this man died.

With the above analytical framework in place, let us return to the two objections, previously outlined, to treating omissions as causes. In relation to the first, as Hart and Honoré noted in Causation in the Law, to state that an agent has not done something is just as much a description of events in the world as the statement that he has done something. ${ }^{17}$ In the former case, however, the description operates by invoking a contrast with, rather than a comparison of, the agent's conduct with the class of actions of that type. That it often makes sense to describe an agent's conduct in such a way is especially clear in those cases where it is expected that an agent in his position would normally do the act in question, but here has omitted to do so. For example, it might well be significant to mention a signalman's failure to pull a lever in seeking an explanation for a train crash. In this case, there will have been a failure to operate a complex man-made system superimposed upon the natural world (the railway) in the manner intended by its designers. In a host of other cases, where it is relevant to focus on omissions, the conventional system of conduct, with which the agent's conduct is contrasted, is one that is put in place by man to hold the natural world at bay. This is because, as Hart and Honoré remark:

"... men have discovered that nature is not only sometimes harmful if we intervene, but is also sometimes harmful unless we intervene, and have developed customary techniques, procedures and routines to counteract such harm. These have become a second 'nature' and so a second 'norm'."'18

There are of course few clearer examples of such "customary techniques, procedures and routines" than the practice of medicine. In terms of the NESS causal model, it is apparent that the failure to invoke such a regime, once available, is causally necessary for the patient's death. Only now is there a complete causal set sufficient for this outcome.

\section{Straightforward basis}

The second objection to treating omissions as causes - that it is arbitrary, in assigning causal status, to isolate the failure of any given individual (as opposed to everyone else) to act so as to forestall a given outcome-challenges us to differentiate among the causal status of multiple omitting agents. However, there is, it is suggested, a straightforward basis upon which such distinctions are made. Suppose, in the example previously cited of a man who takes poison, that, after doing so, he is examined by a doctor. The doctor has an antidote readily to hand, but for malicious reasons fails to administer it and the man dies. It is certainly true that, as well as the omission of the particular doctor, the patient's death would not have occurred if some other agent had intervened and administered the antidote in his stead (ie the absence of the latter is also a necessary condition). However, to elevate the omissions of such hypothetical agents to causal status is senseless in circumstances such as these: there was never any expectation that any other agent would intervene; no such other agent was charged with the responsibility to do so, and, in most cases, will have had no opportunity in any case. Hart and Honoré give the example of a gardener who, by failing to water his flowers, allows them to die. As they state: 
"The 'failure' on the part of persons other than the gardener to water the flowers would ... be a normal though negative condition and, just because such conditions are normal, no mention of them would usually be made. The gardener's failure to water the flowers, however, stands on a different footing. It is not merely a breach of duty on his part, but also a deviation from a system or routine." 17

Here, Hart and Honoré suggest that, in attributing causal status to some necessary conditions within causal set while ignoring others, we focus on those elements that represent a deviation from the norm. Subsequently, Joel Feinberg has distinguished three criteria, which he dubs, respectively, "lantern", "handle", and "stain" criteria, employed by us for these purposes: a member of a causal set sufficient for the outcome will be treated as a cause in so far as it has explanatory force from the inquirer's point of view and/or allows us to control the occurrence of such outcomes and/or is relevant in allocating blame to a human agent. ${ }^{19}$ On this account we are amply justified, in cases where treatment is available to prolong life, in citing the failure of a doctor to treat the patient, as a cause of the latter's death.

Although neither objection to treating omissions as causes thus works as it stands, it is submitted that together they point to a further analysis according to which omissions turn out to enjoy an essentially secondary causal status to acts. Most importantly, it is apparent that, given their negative nature, before omissions can figure in a causal set sufficient for some harm, the risk of such harm, generally in the form of a positive cause (as distinct from mere background conditions), must already be present. The failure to provide someone with medical assistance cannot by itself cause that person's death: he must first be in need of life-saving treatment through illness or otherwise. In fact, the agent who fails, through omission, to prevent death is allowing the completion (his non-intervention is necessary for this) of a pre-existing causal set for that outcome. By contrast, the agent who causes death by an act, for example by administering a lethal injection, typically instigates a causal set for the same result: his act is sufficient to produce it in conjunction with background conditions alone.

\section{Profound consequences}

This difference can sometimes have profound consequences in determining the individual authorship of outcomes. In particular, in the case of failure to provide medical treatment, the "authorship" of an omitting agent lapses in the absence of a socially imposed duty to act. The same is not true of an agent who acts in the absence of a duty not to act. For example, consider a doctor, W, whose patient, $\mathrm{X}$, is being maintained on a ventilator and will die if such support is discontinued. As we have seen, if W removes the support and the patient dies, then to hold W responsible requires us to ascribe causal status to his omission, while regarding the concurrent omissions of all other agents as (collectively) a mere negative background condition. Usually this is easily done: $\mathrm{W}$ alone is the doctor involved with the responsibility and opportunity to keep X alive. Suppose, however, that the quality of X's life was so poor that we believed W should be released from his duty to treat. There is no longer any reason to distinguish between his omission and those of other agents: all are actual omissions, which permit the completion of a causal set for X's death. Secondly, imagine that law reform occurs, such that active euthanasia becomes acceptable and normal, and that another doctor, Y, thereupon gives his patient, $\mathrm{Z}$ (who, like $\mathrm{X}$, has a very poor quality of life), a lethal injection. Let us suppose further that, if he had not done so, some other agent would have taken it upon himself to give $\mathrm{Z}$ the injection instead. Here, by contrast with $\mathrm{W}$ in the first example, $\mathrm{Y}$ remains the author of Z's death: of all the possible acts of lethal injection his was the only actual one in a causal set sufficient for Z's death. The "act" of (lethal injection by) any other agent here remains only hypothetical.

\section{The equality principle}

The above argument, if correct, establishes that a necessary link exists between an act and causal authorship for its outcome, which is not present (at any rate in the absence of a duty to act) in the case of an omission that causes the same outcome. We must now consider what moral significance can be attached to the presence of such authorship.

A purely consequentialist approach would deny that there is any moral significance. On this view it is the outcome alone that ultimately matters morally, not the detail of how it was produced, or who produced it. As James Rachels argues: "If it would be good for a particular state of affairs to occur 'naturally', without being brought about by human action, then it is permissible to act so as to bring it about" ${ }^{20} \mathrm{He}$ suggests that opposition to this "Principle of Agency" is based on no more than "vestigial religion": "It is as though people were thinking of nature as a great mysterious force with its own special kind of moral authority. Hence we have one standard for "what nature does"-in the main, we must accept it and live with it - and a different way of thinking about what we do." ${ }^{21}$ However, contrary to this analysis, it is suggested that, at least in the specific context of bringing about the death of another human being, a principle can be found, which explains on a secular level why active euthanasia is considered problematic in a way that passive euthanasia is not.

The principle in question is that of "equality". According to this, the life of each individual has an equal claim to a minimum respect by possessing irreducible value (ie a value that cannot be fully cashed out in terms of the life-holder's own states of consciousness, pleasurable or otherwise). ${ }^{22}$ An agent who engages in active euthanasia (even at the behest of the deceased) fails to show this respect, for, in assuming authorship over that other's death, he automatically accords his own life an ontological priority: he draws upon his own resources (for which his life is, of course, a precondition) in such 
a way as to extinguish the life of the other. This breaching of the equality principle amounts, it is submitted, to a prima facie reason against any killing, and one which persists even if, in all the circumstances, we are disposed morally to excuse a particular killing. Consider, for example, the following hypothetical case proposed by Dan Brock:

"A patient is dying from terminal cancer, undergoing great suffering that cannot be relieved without so sedating him that he is unable to relate in any way to others. This patient prepared an advance directive at an early stage of his disease indicating that in circumstances like this he wanted to have his life ended either by direct means or by withdrawing life-sustaining treatment. In a recent lucid moment he reaffirmed the directive. The attending physician and the patient's family are in agreement that the patient's desire to die ought now to be granted." ${ }^{23}$

Brock offers two alternative conclusions to this case. In the first, the man's wife places a pillow over his face and asphyxiates him while he is asleep. In the second, the man develops breathing problems (while unconscious) and needs placing on respirator to prolong his life. His wife, who is present and knows this, fails to alert the medical staff and the man dies. Brock goes on to ask if there is "any reason why what the wife does in the first instance is morally (as opposed to legally) worse or different to what she does in the second instance". The answer (and remember the question is not whether, in the first instance as well, we should not morally excuse her action) is surely simply that in the first instance, by assuming authorship over the man's death, she infringes the equality principle. In the second instance she does not.

Finally, it is apparent that this principle, with its stress upon the equal claim to protection that each individual enjoys from violation by others, is one that has a strong appeal in legal terms. In its 1994 report, the House of Lords Select Committee on Medical Ethics described society's prohibition of intentional killing as "the cornerstone of law and social relationships. It protects each of us impartially, embodying the belief that all are equal". ${ }^{24}$ The arguments presented in this paper support the view that, leaving aside policy considerations of a pragmatic nature, the distinction drawn by the law between active and pas- sive euthanasia, is one which is both coherent and defensible at a fundamental level.

Marc Stauch, MA(Oxon) is a Solicitor and Senior Lecturer in Law, Department of Academic Legal Studies, The Nottingham Trent University, Nottingham.

\section{References and notes}

1 (1992) 12 Butterworths Medico-legal reports 38.

2 [1993] 1 All England law reports 821 .

3 Select Committee on Medical Ethics. Report of the Select Committee on Medical Ethics. House of Lords paper no 21. London: HMSO, 1994.

4 See generally, Finnis JM. Bland: crossing the Rubicon? Law Quarterly Review 1993;109:329. Keown J. Restoring moral and intellectual shape to the law after Bland. Law Quarterly Review 1997; 113:481

5 See generally Harris J. The value of life: an introduction to medical ethics. London: Routledge and Kegan Paul, 1985; Singer P. Rethinking life and death. Oxford: Oxford University Press, 1995.

6 See reference 2: 885 .

7 See reference $2: 884$

8 Williams G. Textbook of criminal law [2nd ed]. London: Stevens, 1983: 282; von Wright GH. Norm and action. London: 1983: 282; von Wright GH. Nor

9 Routledge and Kegan Pau

$\begin{aligned} & 9 \text { See reference 2: 867-8. } \\ & 10 \text { Brock DW. Life and death. Cambridge: CUP, 1993: } 209 .\end{aligned}$

11 Kennedy I, Grubb A. Medical law [2nd ed]. London: Butterworths, 1994: 1210-11.

12 Subject to a Bodkin-Adams style defence, which may apply in imited circumstances: see further Ferguson PR. Causing death or allowing to die? Fournal of Medical Ethics 1997; 23:368-72.

13 See Rachels J. Active and passive euthanasia. New England fournal of Medicine 1975;292,2:292.

14 See Mack E. Bad Samaritans and the causation of harm. Philosophy \& Public Affairs 1980;9:230.

15 For a thorough analysis of the arguments, see Kuhse H. The sanctity of life doctrine in medicine. Oxford: Clarendon Press, 1987: ch 2 .

16 See Wright R. Causation in tort law. Californian Law Review 1985;73:1735; Honoré T. Necessary and sufficient conditions. In: Owen DG, ed. Philosophical foundations of tort law. Oxford: In: Owen DG, ed. Philos

17 Hart HLA, Honore T. Causation in the law [2nd ed]. Oxford: Clarendon Press, 1985: 38.

18 See reference $17: 37$.

9 Feinberg J. Harm to others. New York: Oxford University Press, 1984: 176-7.

20 Rachels J. The principle of agency. Bioethics 1998;12,2:150161: at 154

21 See reference 20: 161

22 Kadish S. Respect for life and regard for rights in the criminal law. In: Temkin O, ed. Respect for life in medicine, philosophy and law. Baltimore: London: Johns Hopkins University Press, 1977: 72.

3 See reference 10: 187-8

24 See reference 3: vol 1, para 237.

\section{News and notes \\ Seventh International Bioethics Seminar}

The Seventh International Bioethics Seminar will be held in Fukui, Japan from November 1 - 3, 2000.

Topics covered will include: Pharmacogenomics; DNA polymorphism and Medical genetic services, policy and ethics.
For further information please contact the Secretariat at: the Department of Medicine, Fukui Medical University, Matsuokacho, 910-1193, Japan. Tel: 81776-61-8351; fax: 81-776-61-8110. 